\title{
ПОЛИТИЧЕСКИЕ ЦИКЛЫ ДЕЛОВОЙ АКТИВНОСТИ: МЕЖДИСЦИПЛИНАРНЫЙ АНАЛИЗ ЭЛЕКТОРАЛЬНЫХ И ПОСТЭЛЕКТОРАЛЬНЫХ ЛЕТ
}

\begin{abstract}
К.В. Рудый*
В статье тестируется гипотеза о политических циклах деловой активности на примере 121 страны за период с 1991 по 2019 г. С помощью регрессионного анализа выявлен бюджетный политический цикл деловой активности для группы стран с высоким уровнем экономического развития. В период с 1992 по 2019 г. выявлены политические циклы деловой активности стран ЕАЭС и Украины: денежный в Беларуси, Кыргызстане, России и Украине, бюджетный в Армении, России и Украине, общеэкономический в Казахстане.
\end{abstract}

Ключевые слова: политические циклы деловой активности, политическая экономия, экономическая политика.

JEL-классификация: D71, Е32, Н5, H6, О50, P16.

DOI: $10.46782 / 1818-4510-2021-1-59-69$

Материал поступил 22.01.2021 2.

Ренессанс политической экономии, как отрасли экономической науки, в последние годы вызван ростом неопределенности и повышением влияния политических процессов в отдельных странах на национальную и мировую экономику. Трампизм, BREXIT, COVID-19 - лишь некоторые яркие примеры, которые вдохновили ученыхэкономистов активизировать междисциплинарные исследования взаимосвязей политики и экономики (Фриден, 2020).

Для постсоветстких стран политическая экономия не теряла своей актуальности ввиду сложности и гибридности их политических и экономических систем. Требование системности социально-экономической политики, учитывающей не только экономические, но и политические, социологические, демографические, научно-технические, институциональные и иные аспекты, постоянно звучит в русскоязычной научной литературе (Клейнер, 2015, 2016; Бузгалин, Колганов, 2016).
Целью данного междисциплинарного исследования является поиск взаимосвязи влияния выборов ключевого политического субъекта в стране с экономической политикой в краткосрочном периоде - в электоральный и постэлекторальные годы. С учетом обзора литературы выдвинута гипотеза о том, что в год выборов у властей появляются стимулы продемонстрировать электорату результаты своей макроэкономической политики (экономический рост, снижение инфляции и безработицы, валютную стабильность, улучшение текущего счета платежного баланса), а также оказать влияние на электорат с помощью экспансионистской экономической политики (увеличивая денежную массу и бюджетные расходы, сокращая налоговую нагрузку). Соответственно, гипотеза предполагает, что в год после выборов эти стимулы пропадают и макроэкономическая среда вместе с экономической политикой делают шаг назад в своей динамике. Таким образом, данная

* Рудый Кирилл Валентинович (kvrudy@gmail.com), доктор экономических наук, профессор, Банк развития Республики Беларусь (г. Минск, Беларусь).

ORCID ID: 0000-0001-8630-2330. 
гипотеза полагает существование политических циклов деловой активности.

Гипотеза тестируется на примере 121 страны за период с 1991 по 2019 г., рассматриваются группа всех стран и их подгруппы в зависимости от уровня экономического развития, принадлежности к демократическим, гибридным и авторитарным системам. Одной из задач статьи является поиск региональной и интеграционной синхронности в политических циклах деловой активности постсоветских стран. В связи с этим проверка гипотезы проводится также на примере Беларуси, России и Украины, стран - членов ЕАЭС в период с 1992 по 2019 г.

\section{Обзор литературь}

В 1970-х годах в публицистике и научной литературе стало популярно понятие политических циклов деловой активности. Тогда в СМИ появился нарратив о том, что в целях переизбрания на очередной срок власти перед выборами оказывают влияние на электорат с помощью экспансионистской экономической политики. Ученые-экономисты взялись тестировать этот тезис. Одной из наиболее цитируемых стала статья Р. Фэйра, который на примере президентских выборов в США показал, что в период с 1916 по 1976 г. 1\% экономического роста давал дополнительно около $1 \%$ голосов в пользу действующей власти, представленной на выборах (Fair, 1978). Ряд экономистов отмечал, что внимание к политическим циклам деловой активности в 1970-е годы было вызвано падением цен на международных товарных и сырьевых рынках, в результате чего власти многих стран больше не могли полагаться на ценовую конъюнктуру, а стали использовать проактивную экономическую политику для демонстрации электорату результатов своей работы (Ales, Maziero, Yared, 2012). Примечательно, что также с 1970-х годов в развитых демократических странах начался рост долга к ВВП, что может свидетельствовать об интенсивном использовании заимствований при проведении этими странами проактивной экономической политики в целях достижения быстрых и обозримых результатов в рамках политических циклов.
В 2010-е годы тематика политических циклов деловой активности актуализировалась в научных исследованиях вместе с падением мировых цен на сырьевые товары, изменением общественных предпочтений в сторону экономической эффективности властей по сравнению с их политической честностью1. Профессор политологии Гарвардского университета М. Сэндэл в своей последней книге назвал «тиранией» меритократию, когда общества ряда стран, оценивающие политиков через экономический рост, уровень доходов и потребления, в итоге стали ощущать свою непричастность к сложным экономическим процессам, снисходительность и бессердечность со стороны либеральных политиковмеритократов (Sandel, 2020). В итоге эти общества начали поворачиваться в сторону демагогии и экономического популизма (Aksoy, Guriev, Treisman, 2018; Guriev, Papaioannou, 2020, Rodrik, 2020) - более упрощенного, вдохновляющего, порой не предполагающего строгого отчета об экономических результатах на выборах, что стало сглаживать политические циклы деловой активности.

Классификацию политических циклов деловой активности можно представить в зависимости от используемых властями к политическим выборам целей, подходов и инструментов экономической политики.

Ряд исследований показывает, что при выборе целей в электоральный период власти часто отдают предпочтение внутренним приоритетам над внешнеэкономическими. Например, Дж. Айзенман и Х. Ито на примере 139 стран за период с 1975 по 2016 г. показали, что власти в рамках политэкономических циклов сталкиваются с трилеммой выбором двух целей из трех. В экономике власти выбирают классически между стабиль-

\footnotetext{
1 Изменение общественных предпочтений от честности политиков к эффективности наблюдается на отдельных примерах данных 6-й и 7-й волн социологического исследования Всемирного обзора ценностей. Если в 20102014 гг. в 27 опрашиваемых странах в среднем 89,9\% респондентов предпочли честные выборы экономическому развитию страны, то в 2017-2020 гг. схожий вопрос о предпочтении честного или эффективного политического лидера был задан только в Мексике. Ответы в пользу честности сократились в Мексике с 92 до 54\% и сместились в сторону предпочтения эффективности политиков. URL: http://www.worldvaluessurvey.org/WVSOnline.jsp
} 
ностью валютного курса, независимостью монетарных властей и финансовой открытостью; в политике - между суверенитетом, глобализацией и демократией (Aizenman, Ito, 2020). Различия в приоритетах позволяют выделить внутренние и внешние политические циклы деловой активности, характеризующие в электоральный период внутри- и внешнеэкономические показатели соответственно. При этом важно отметить, что приоритет внутренних показателей над внешнеэкономическими в электоральный период не является общим правилом и, как будет видно далее, не всегда подтверждается статистически.

Есть исследования, показывающие, что власти к выборам, с одной стороны, пытаются сформировать стабильную макроэкономическую среду, обеспечить финансовую и валютную стабильность, в том числе иногда путем фиксации курса национальной валюты, и стимулировать экономический рост (Schamis, Way, 2003). С другой стороны, власти используют инструменты экономической политики для прямого влияния на электорат в виде увеличения бюджетных расходов (как общих, так, в частности, и социальных, например пенсий, пособий по безработице, зарплат госслужащих), сокращения налогов (Rogoff, 1990), увеличения кредитования, особенно через государственные банки (Koetter, Popov, 2020). В научной литературе встречаются исследования отдельных видов политических циклов деловой активности. Например, бюджетного, пики которого в виде изменений налоговых доходов, бюджетных расходов, бюджетного дефицита были зафиксированы в годы выборов в группе стран с небольшим опытом демократии (Brender, Drazen, 2004), или денежного, учитывающего изменение денежной массы, инфляцию (Alesina, Cohen, Roubini, 1992).

Политические циклы деловой активности характерны для стран с разным уровнем экономического и политического развития. Страны с низким уровнем экономического развития испытывают свойственные им проблемы высокой инфляции, девальвации национальной валюты, поэтому в электоральный период приоритет часто отдают валютно-финансовой стабильно- сти для обеспечения роста реальных доходов избирателей. В свою очередь, страны с высоким уровнем экономического развития, как правило, концентрируются на количестве созданных рабочих мест, уровне безработицы ${ }^{2}$. Страны с разными политическими системами также имеют разную мотивацию использовать экономические инструменты в электоральный период. Например, в более демократических странах экономические инструменты ориентированы на электорат, в менее демократических - на систему управления. Имеются исследования, в которых отмечается, что выборы необходимы властям в странах, относящихся к недемократическим, для тестирования дееспособности политической системы, перераспределения власти в элитах, сбора информации о проблемах на местах (Egorov, Sonin, 2020), проверки лояльности местных органов власти (Geddes, 2018, Thornhill, Smirnova, 2018).

\section{Гипотеза и методика тестирования}

С учетом обзора литературы далее тестируется гипотеза о политических циклах деловой активности (далее - гипотеза). Гипотеза заключается в том, что в год выборов власти пытаются продемонстрировать избирателям положительные результаты своей работы в экономике - благоприятную макроэкономическую среду и финансовую стабильность, например экономический рост, снижение безработицы и инфляции, стабильность валютного курса, улучшение внешнеторгового сальдо. Одновременно в электоральный год в целях более ощутимого прямого влияния на избирателей власти предположительно увеличивают бюджетные расходы, снижают налоговую нагрузку, расширяют денежную массу. Эта гипотеза также предполагает, что в год после выборов у властей снижаются стимулы использования вышеназванных экономических инструментов и они менее

2 Этот показатель политического цикла деловой активности получил свое широкое признание в 1991 г., когда, по мнению экспертов, именно низкий уровень безработицы стал причиной того, что Дж.Буш старший не смог переизбраться в США, несмотря на то, что его первый срок пришелся на победу США в холодной войне и в первой войне в Персидском заливе (Rajan, 2011). 
заботятся о краткосрочных результатах, поэтому такие экономические показатели могут ухудшаться в постэлекторальный год. С учетом экономических приоритетов и политических ориентиров властей предполагается, что политические циклы деловой активности будут иметь свои особенности в странах с разным уровнем экономического и политического развития.

Гипотеза тестируется здесь на примеpe 121 страны за период с 1991 по 2019 г. Все они были разделены на парламентские и президентские и оценивались в двух сроках: в год выборов и в год, следующий за выборами. При этом в парламентских странах для анализа использовались даты выборов в парламент, а в президентских соответственно, президента. Данные по выборам брались на основе методики (Beck, Clarke, Groff, Keefer, Walsh, 2001)3. Политические показатели уровня развития демократии были взяты из методики Тhe Economist Intelligence Unit ${ }^{4}$, экономические - из данных Всемирного банка ${ }^{5}$. При анализе стран с разными уровнями демократии с учетом доступности информации использовался не 29-летний, как для других групп стран, интервал, а более короткий 12летний период анализа: 2006, 2008, 2010 2019 гг.

Исследование опиралось на многофакторный линейный регрессионный анализ с помощью компьютерной программы SPSS Statistics. Данный метод часто применялся в схожих исследованиях политических циклов деловой активности (Persson, Tabellini, 2003; Brender, Drazen, 2004). Независимыми переменными предикторами были:

$L g d p \_p$ - десятичный логарифм ВВП по ППС на душу населения в текущих международных долларах;

$T r$ - сумма экспорта и импорта товаров и услуг в \% к ВВП;

3 Данные за 1991-2017 гг.: The Database of Political Institutions 2017. 2018. Inter-American Development Bank. URL: https://www.scilit.net/journal/2848398; за 2018-2019 гг.: URL: https://en.wikipedia.org/wiki/List_of_the_most_recent_ elections_by_country

${ }^{4}$ Democracy Index 2019. 2020 A Year of Democratic Setbacks and Popular Protest. URL: https://www.in.gr/wpcontent/uploads/2020/01/Democracy-Index-2019.pdf

${ }^{5}$ URL: https://data.worldbank.org/
Pp15, Pp65 - два демографических показателя, характеризующих отношение численности населения младше 15 лет к населению в трудоспособном возрасте от 15 до 64 лет, а также отношение численности населения старше 64 лет к населению в возрасте от 15 до 64 лет;

GDP_HP - циклическая составляющая в динамике реального ВВП, рассчитываемая как разница между десятичным логарифмом ВВП по ППС в текущих международных долларах и данным показателем, очищенным фильтром Ходрика-Прескотта;

Elec $Y$ - булева переменная со значением 1 в год президентских выборов в президентских странах и в год парламентских выборов в парламентских странах, 0 - в иные годы;

$\operatorname{Elec}(Y+1)$ - булева переменная со значением 1 в следующий год после президентских выборов в президентских странах и в следующий год после парламентских выборов в парламентских странах, 0 - в иные годы.

К числу зависимых переменных были отнесены следующие показатели, характеризующие политические циклы деловой активности. Общий политический цикл деловой активности:

$E c o n \_G r$ - прирост реального ВВП в \%;

Unempl - \% безработных к общему числу трудовых ресурсов.

Бюджетный политический цикл деловой активности: ВВП;

Expens - бюджетные расходы в \% к

Tax - налоговые доходы в \% к ВВП.

Денежный политический цикл деловой активности:

CPI - индекс потребительских цен в $\%(2010=100 \%)$ ВВП;

$B r \_m$ - денежный агрегат M3 в \% к

$E x \_R t$ - обменный курс национальной валюты к доллару США.

Внешнеторговый политэкономический цикл:

$C A$ - сальдо счета текущих операций платежного баланса в \% к ВВП.

Для выявления особенностей политических циклов деловой активности в разных странах последние были разделе- 
ны на несколько групп. По уровню экономического развития: одна группа - с высоким уровнем развития (согласно классификации Всемирного банка в 2019 г. по номинальному ВНД на душу населения по методу Атласа более 12,3 тыс. долл. США), вторая группа - со средним и низким уровнем (показатель - менее 12,3 тыс. долл. США). По уровню политического развития: одна группа - страны с демократическим режимом (согласно классификации EIU в 2019 г. ${ }^{6}$ со значением индекса более 6), вторая группа - с гибридным и авторитарным режимом (со значением индекса менее 6).

В поисках интеграционной политэкономической синхронности стран - участниц ЕАЭС (Армении, Беларуси, Казахстана, Кыргызстана и России), а также региональной (Беларусь, Россия, Украина) гипотеза была также протестирована на примере этих стран за период с 1992 по 2019 г.

\section{Результаты тестирования гипотезь}

В результате тестирования гипотезы о политических циклах деловой активности из всех видов циклов в разных группах стран свое подтверждение получил только бюджетный политический цикл деловой активности в части показателя бюджетных расходов к ВВП в группе стран с высоким уровнем экономического развития. Из 80 эпизодов расчетов регрессии только в 8 случаях был получен коэффициент детерминации (скорректированный $R^{2}$ ) на уровне, близком к 0,7 , чтобы делать относительные выводы о достоверности полученных результатов. Bсе эти 8 эпизодов свойственны бюджетному политическому циклу деловой активности. В 10 из 80 случаев коэффициент детерминации находился в пределах 0,3-0,6 и был характерен для показателя безработицы в странах с высоким уровнем развития, показателя налоговой нагрузки в странах с низким уровнем экономического и политического развития,

${ }^{6}$ Democracy Index 2019. 2020 A Year of Democratic Setbacks and Popular Protest. URL: https://www.in.gr/wpcontent/uploads/2020/01/Democracy-Index-2019.pdf а также показателя текущего счета платежного баланса в странах с авторитарными и гибридными политическими системами. В остальных 62 случаях коэффициент детерминации был менее 0,3 , что говорит о недостоверности результатов тестирования.

То, что гипотеза оказалась недостоверной в части взаимосвязи экономического роста и уровня безработицы с электоральным и постэлекторальным периодами, подтверждается и иными исследованиями. Например, в работе А. Алесины, Дж. Коэна и Н. Рубини также не было найдено свидетельств сокращения безработицы и увеличения экономического роста к политическим выборам в группе из 18 стран ОЭСР. При этом названным ученым в указанной выборке стран удалось наблюдать экспансионистскую монетарную политику в год выборов, а также всплеск инфляции после выборов (Alesina, Cohen, Roubini, 1992, 1997). Здесь этот вывод не подтвердился для 121 страны на 12-летнем и 29-летнем периодах.

Метод многофакторного линейного регрессионного анализа бюджетных расходов, в статистическую модель которой также был включен независимый предиктор Tax - налоговые доходы в \% к ВВП, дал результаты, представленные в таблице. Наибольший коэффициент детерминации $(0,69)$ получен для демократических стран за 12-летний период. При этом в данном случае страны не увеличивали, а сокращали бюджетные расходы в электоральный и постэлекторальный годы. Для группы всех стран за 29-летний период коэффициент детерминации составил 0,64, и власти этих стран увеличивали бюджетные расходы в год выборов по сравнению с иными годами на 0,24\%, а также в год, следующий за выборами, на $0,16 \%$, т. е. в меньшей степени, чем в электоральный год. Несмотря на относительно невысокое значение показателя качества оценки $R^{2}$, но с учетом отсутствия мультиколлинеарности (была проанализирована матрица парных коэффициентов корреляции), можно сделать следующий вывод. Такая динамика роста бюджетных расходов в электоральный год и их за- 
медление в постэлекторальный подтверждают наличие бюджетного политического цикла деловой активности в странах с высоким уровнем экономического развития. Страны с высоким уровнем развития увеличивали бюджетные расходы больше в год выборов, чем в год после выборов, а страны со средним и низким уровнем развития - наоборот, больше в год после выборов, чем в год выборов. Если сравнить полученные результаты тестирования с иными исследованиями, проведенными схожим статистическим методом, то получается, что этот показатель со временем вырос. Например, в работе А. Брендера и А. Дразена выявлено, что за период с 1960 по 2001 г. на выборке из 1638 наблюдений в 68 странах бюджетные расходы к ВВП в год выборов по сравнению с иными периодами росли на 0,07\% (Brender, Drazen, 2004).

\section{Результаты тестирования гипотезы для стран ЕАЭС и Украины}

В поисках интеграционной и региональной синхронности политических циклов деловой активности далее гипотеза тестировалась на примере стран ЕАЭС (Армения, Беларусь, Казахстан, Кыргызстан, Россия) и Украина.

\section{Армения}

Тестирование гипотезы на примере Армении в 1992-2019 гг. в электоральных периодах показало высокие коэффициенты детерминации (скорректированный $R^{2}$ ) по следующим показателям: налоговая нагрузка $(0,965)$, бюджетные расходы $(0,96)$, инфляция $(0,959)$, уровень безработицы $(0,885)$, валютный курс $(0,853)$. В Армении наблюдается бюджетный политический цикл деловой активности в части измене-

Результаты многофакторного регрессионного анализа бюджетных расходов

Таблица

\begin{tabular}{|c|c|c|c|c|c|c|c|c|}
\hline \multirow{2}{*}{ Expens } & \multicolumn{2}{|c|}{ Все страны } & \multicolumn{2}{|c|}{$\begin{array}{l}\text { Страны с высоким } \\
\text { уровнем развития }\end{array}$} & \multicolumn{2}{|c|}{$\begin{array}{c}\text { Страны со средним } \\
\text { и низким уровнем } \\
\text { развития } \\
\end{array}$} & \multicolumn{2}{|c|}{$\begin{array}{c}\text { Страны } \\
\text { с демократической } \\
\text { системой }\end{array}$} \\
\hline & ElecY & $\operatorname{Elec}(Y+1)$ & Elec $Y^{*}$ & $\operatorname{Elec}(Y+1)^{*}$ & ElecY & $\operatorname{Elec}(Y+1)$ & Elec $Y^{*}$ & $\operatorname{Elec}(Y+1)^{*}$ \\
\hline $\begin{array}{l}\text { Коэффициент } \\
B\end{array}$ & 0,243 & 0,157 & 0,396 & 0,076 & 0,077 & 0,202 & $-0,222$ & $-0,288$ \\
\hline T-статистика & 0,704 & 0,453 & 0,674 & 1,3 & 0,193 & 0,502 & $-0,466$ & $-0,601$ \\
\hline $\begin{array}{l}\text { Скорректиро- } \\
\text { ванный } R^{2}\end{array}$ & 0,642 & 0,642 & 0,605 & 0,605 & 0,608 & 0,608 & 0,690 & 0,690 \\
\hline F-статистика & 498,082 & 497,966 & 183,361 & 183,201 & 244,999 & 245,078 & 197,482 & 197,549 \\
\hline $\begin{array}{l}\text { Количество } \\
\text { стран }\end{array}$ & 107 & 107 & 46 & 46 & 77 & 77 & 66 & 66 \\
\hline $\begin{array}{l}\text { Количество } \\
\text { наблюдений }\end{array}$ & 1945 & 1945 & 834 & 834 & 1101 & 1101 & 618 & 618 \\
\hline $\begin{array}{l}\text { Период } \\
\text { наблюдений, } \\
\text { лет }\end{array}$ & 29 & 29 & 29 & 29 & 29 & 29 & 12 & 12 \\
\hline
\end{tabular}

* Значим на уровне $1 \%$.

Примечание. Expens - зависимая переменная; ElecY $(\operatorname{Elec}(Y+1))$ - независимые переменные; также в статистическую модель вошли: $\operatorname{Tax}, \operatorname{Lg} d p \_p c, \operatorname{Tr}, \operatorname{Pp} 15, \operatorname{Pp} 65, \mathrm{GDP} \mathrm{HP}_{\text {. }}$

Источник. Расчеты автора. 
ния налоговой нагрузки, когда налоговые поступления к ВВП снижались в год выборов относительно иных периодов, причем более высоким темпом, чем в год после выборов. В свою очередь, бюджетные расходы в электоральные периоды в Армении не увеличивались, а сокращались, что не позволяет говорить об их политической цикличности. Снижение бюджетных расходов, тем не менее, не позволило в год выборов в Армении сокращать инфляцию, которая росла быстрее, чем в иные периоды, и даже опередила свой рост в год после выборов. Также в электоральные периоды властям не удалось обеспечить валютную стабильность: курс национальной валюты существенно колебался как в год выборов, так и после. В электоральные периоды в Армении удалось сократить уровень безработицы, но в год выборов меньше, чем в послевыборный год, что не подтверждает политическую цикличность данного показателя.

По параметрам экономического роста, денежной массы и текущего счета платежного баланса статистически значимых результатов на данном примере получено не было.

\section{Беларусь}

По итогам тестирования гипотезы на примере Республики Беларусь за период с 1992 по 2019 г. один из высоких коэффициентов детерминации $(0,885)$ был получен при исследовании бюджетных расходов к ВВП в электоральные периоды. По полученным данным, наличия гипотетического бюджетного политического цикла деловой активности с ростом бюджетных расходов в Беларуси не выявлено, так как бюджетные расходы были меньше как в год выборов, так и после них, относительно иных периодов, что, вероятно, связано с иными приоритетами экономической политики, например ценовой и валютной стабильностью. Исследование валютного курса также показало высокий коэффициент детерминации $(0,904)$. При этом в электоральные периоды не удавалось обеспечить валютной стабильности: курс национальной валюты к доллару США колебался относи- тельно иных периодов значительно как в год выборов, так и в год после выборов. Спецификой Беларуси можно назвать наличие денежного политического цикла деловой активности по показателю денежной массы (с коэффициентом детерминации равным 0,754). В год выборов денежная масса в Беларуси увеличивалась по сравнению с иными периодами, причем большим темпом, чем она росла в год после выборов. Также был выявлен достаточно значимый коэффициент детерминации при исследовании уровня безработицы $(0,847)$, которая сокращалась в год выборов относительно иных периодов. Однако в связи с долгосрочным использованием в Беларуси в качестве параметра безработицы уровня официально зарегистрированной безработицы, а не опроса домашних хозяйств, этот показатель здесь сложно отнести к результатам экономической политики в электоральные периоды.

По иным показателям экономического роста, налоговой нагрузки, текущего счета платежного баланса, инфляции в Беларуси в электоральные периоды статистически значимых результатов выявлено не было.

\section{Россия}

Тестирование гипотезы на примере России за период с 1992 по 2019 г., как и в случае Беларуси, показало высокие коэффициенты детерминации в электоральные периоды в денежной сфере. Скорректированный $R^{2}$ при регрессионном анализе показателя денежной массы составил 0,936. При этом денежная масса в год президентских выборов в России сокращалась, а не росла относительно других периодов, и быстрее, чем в год после выборов. Это отразилось на динамике инфляции, которая (при коэффициенте детерминации 0,984) снижалась в год выборов, относительно иных периодов, но меньше, чем в год после выборов. При анализе экономической политики России важно учитывать взаимосвязь динамики сальдо текущего счета платежного баланса с налоговыми поступлениями и курсом российского рубля (в трех случаях получены высокие показатели скорректированного $R^{2}-0,819,0,836$ и 
0,879 соответственно). Текущий счет платежного баланса в России улучшался в год выборов по сравнению с иными периодами и с годом после выборов. В связи с тем, что внешнеторговое сальдо в России преимущественно зависит от динамики цен на сырьевые ресурсы, влияние властей на которые ограничено, то едва ли на этом примере можно считать изменение данного показателя полноценным внешнеэкономическим политическим циклом деловой активности. Поступления валютных ресурсов от улучшения текущего счета платежного баланса позволили российским властям в электоральный период обеспечить валютную стабильность - незначительное укрепление российского рубля в год выборов на 0,4\% по сравнению с иными периодами, что меньше, чем в год после выборов - на 2,29\%. В свою очередь, налоговая нагрузка в год выборов в России снижалась относительно иных периодов, а в год после выборов увеличивалась, что может свидетельствовать о наличии в стране бюджетного (в части налоговой нагрузки) политического цикла деловой активности. Еще один показатель с высоким коэффициентом детерминации $(0,892)$, уровень безработицы, увеличивался в год выборов относительно иных периодов и больше, чем в год после выборов, что не подтверждает выдвинутую гипотезу о политической цикличности.

По показателям экономического роста и бюджетных расходов в электоральных периодах в России статистически значимых результатов получено не было.

\section{Казахстан}

В Казахстане за период с 1992 по 2019 г. в рамках тестирования гипотезы высокие коэффициенты детерминации получены только по двум показателям: безработица $(0,903)$ и денежная масса $(0,815)$. По первому показателю фиксируется политическая цикличность, когда безработица снижается в год выборов быстрее иных периодов, а в год после выборов также сокращается, но уже меньшими темпами. Что касается денежной массы, то власти Казахстана увеличивают данный параметр в год выборов почти на 1\% больше, чем в иные пери- оды. Однако в год после выборов этот параметр увеличивается еще больше - на 2,8\% по сравнению с иными периодами, поэтому в Казахстане, строго говоря, не просматривается денежный политический цикл деловой активности.

Остальные тестируемые показатели экономического роста, инфляции, валютного курса, текущего счета платежного баланca, бюджетных расходов и налоговой нагрузки не дали при тестировании гипотезы в Казахстане значимых статистических результатов.

\section{Кыргызстан}

С учетом наличия сопоставимых данных в Кыргызстане в 1992-2019 гг. тестирование гипотезы позволило получить в электоральные периоды высокие коэффициенты детерминации исключительно по денежным показателям: инфляция $(0,992)$, денежная масса $(0,954)$, валютный курс (0,781). Денежный политический цикл деловой активности подтверждается меньшей инфляцией в Кыргызстане в год выборов по сравнению с иными периодами на 1,1\%, а в год после выборов - также меньшей на 0,2\%, но выше, чем в год выборов. С учетом приоритета инфляции в электоральные периоды денежная масса также была не больше, а меньше как в год выборов, так и после. Кроме того, в Кыргызстане в электоральные периоды властям удавалось обеспечить валютную стабильность, при которой в год выборов курс национальной валюты девальвировался всего на 1\%, а после выборов - ревальвировался на $3 \%$.

По показателям экономического роста, безработицы, текущего счета платежного баланса, бюджетных расходов и налоговой нагрузки статистически значимых при проверке гипотезы на примере Кыргызстана результатов получено не было.

\section{Украина}

По итогам тестирования гипотезы в Украине в период с 1992 по 2019 г. получены высокие коэффициенты детерминации в электоральные периоды в денежной сфере: валютный курс $(0,961)$, денежная 
масса $(0,917)$, инфляция $(0,918)$. Спецификой Украины является наличие валютного политического цикла экономической активности: власти обеспечивали валютную стабильность в электоральные периоды, допуская девальвацию национальной валюты в год президентских выборов всего на 0,015\% относительно иных периодов, а в год после выборов - на 0,5\%. Денежная масса увеличивалась в год выборов, но чуть меньшим темпом, чем в год после выборов, что не позволяет говорить о строгой цикличности в этой сфере. При этом рост денежной массы не приводил к инфляции, которая снижалась в год выборов относительно иных периодов, хотя и меньшим темпом, чем это происходило в год после выборов. Бюджетная сфера также показала высокие показатели скорректированного $R^{2}$ в электоральные периоды: бюджетные расходы (0,912), налоговая нагрузка $(0,827)$. Бюджетные расходы в год выборов в Украине не росли, а сокращались. По показателю налоговой нагрузки в стране наблюдался бюджетный политический цикл деловой активности, когда налоговая нагрузка снижалась в год выборов, а затем увеличивалась в год после выборов.

По иным рассматриваемым в гипотезе показателям экономического роста, безработицы и текущего счета платежного баланса статистически значимых результатов на примере Украины получено не было.

Анализируя результаты тестирования гипотезы по шести странам, сложно сделать однозначный вывод о региональной и интеграционной синхронности политических циклов деловой активности в них. Общим для всех рассмотренных стран является отсутствие статистически значимых результатов по влиянию электоральных периодов на экономический рост, что говорит как о сложности самого показателя, так и ограниченных возможностях управления им. Полноценная цикличность показателя безработицы в электоральные периоды наблюдалась только в Казахстане. Общей и исключительной интеграционной и региональной синхронности политических циклов деловой активности в странах ЕАЭС и в восточноевропейском регионе (Беларусь, Россия, Украина) выявлено не было. Со- впадение цикличности отмечается в денежной сфере в электоральные периоды по обеспечению валютной стабильности в Кыргызстане, России и Украине. Беларусь в данной сфере имеет специфику в части циклического использования денежной массы в периоды выборов. Определенные совпадения отмечаются в бюджетном политическом цикле деловой активности в части использования на выборах инструмента налоговой нагрузки в Армении, России и Украине.

По итогам междисциплинарного анализа электоральных и постэлекторальных лет на примере 121 страны за период с 1991 по 2019 г. можно сделать общий вывод, скорее, об отсутствии политических циклов деловой активности, нежели об их наличии. В 72 из 80 случаев регрессионного анализа не было получено статистически значимых результатов. На этих данных, а также отдельно на данных по 6 странам в период с 1992 по 2019 г. подтвердились результаты ранее проводимых исследований об отсутствии общего влияния электоральных периодов на экономический рост и уровень безработицы (политическая цикличность показателя безработицы выявлена лишь в Казахстане).

Выдвинутая гипотеза об активизации экспансионистской экономической политики в год выборов и ее сокращении в год после выборов частично подтвердилась для группы стран с высоким уровнем экономического развития на 29-летнем периоде в части использования инструмента бюджетных расходов. При этом полученные результаты позволили наблюдать в 19912019 гг. более высокие пики бюджетного политического цикла деловой активности, чем они просматривались в других исследованиях за период с 1960 по 2001 г.

При анализе региональной и интеграционной специфики политических циклов деловой активности в восточноевропейских странах (Беларуси, России, Украины), а также в странах ЕАЭС общей политэкономической синхронности выявлено не было. Совпадения обнаружены в обеспечении властями валютной стабильности в год вы- 
боров в Кыргызстане, России и Украине, а также в использовании инструмента налоговой нагрузки в электоральный период в Армении, России и Украине.

\section{СПИСОК ЛИТЕРАТУРЫ (REFERENCES)}

Бузгалин А.В., Колганов А.И. 2016. Политическая экономия и экономическая политика. Рынок. Капитал. Общество. Terra Economicus. Т. 14. № 1. C. 27-47. [Buzgalin A.V., Kolganov A.I. 2016. Political economy and economic policy. Market. State. Society. Terra Economicus. Vol. 14. No 1. PP. 27-47. (In Russ.)]

Клейнер Г.Б. 2015. Устойчивость российской экономики в зеркале системной экономической теории (Часть 1). Вопросы экономики. № 12. C. 107-123. [Kleiner G.B. 2015. Sustainability of Russian economy in the mirror of the system economic theory (Part 1). Voprosy ekonomiki. No 12. PP. 107-123. (In Russ.)]

Клейнер Г.Б. 2016. Устойчивость российской экономики в зеркале системной экономической теории (Часть 2). Вопросы экономики. № 1. C. 117-138. [Kleiner G.B. 2016. Sustainability of Russian economy in the mirror of the system economic theory (Part 2). Voprosy ekonomiki. No 1. PP. 117138. (In Russ.)]

Фриден Дж. 2020. Политическая экономия экономической политики. Финансы и развитие. C. 4-9. [Frieden J. 2020. Political economy of economic policy. Finansy i razvitie. PP. 4-9. (In Russ.)]

Aizenman J., Ito H. 2020. The Political-Economy Trilemma. NBER Working Paper. No 26905. 45 p.

Aksoy C.G., Guriev S., Treisman D.S. 2018. Globalization, Government Popularity, and the Great Skill Divide. NBER Working Paper. No 25062. 65 p.

Ales L., Maziero P., Yared P. 2012. A Theory of Political and Economic Cycles. NBER Working Paper. No 18354. 66 p.

Alesina A., Cohen G., Roubini N. 1992. Macroeconomic Policy and Elections in OECD Democracies. Economic E Politics. Vol. 4. Iss. 1. PP. 1-30.

Alesina A., Roubini N., Cohen G. 1997. Political Cycles and the Macroeconomy. Cambridge, MA: MIT Press. 302 p.
Beck T., Clarke G., Groff A., Keefer Ph., Walsh P. 2001. New Tools in Comparative Political Economy: The Database of Political Institutions. The World Bank Revier. Vol. 15. No 1. PP. 165-176.

Brender A., Drazen A. 2004. Political Budget Cycles In New Versus Established Democracies. NBER Working Paper. No 10539. 46 p.

Egorov G., Sonin K. 2020. The Political Economics of Non-Democracy. NBER Working Paper. No 27949. 55 p.

Fair R. 1978. The Effect of Economic Events on Votes for President. Review of Economics and Statistics. Vol. 60. No 2. PP. 159-173.

Geddes B. 2018. Why dictators hold semicompetitive elections and encourage the use of semiindependent courts: a comment on Thornhill and Smirnova's «litigation and political transformation». Theory and Society. Vol. 47. PP. 595-601.

Guriev S., Papaioannou E. 2020. The Political Economy of Populism. CEPR Discussion Paper. No DP14433.

Koetter M., Popov A. 2020. Political Cycles in Bank Lending to the Government. The Review of Financial Studies. URL: http://doi.org/10.1093/rfs/ hhaa118

Persson T., Tabellini G. 2003. Do Electoral Cycles Differ Across Political Systems? IGIER Working Paper. No 232. 24 p.

Rajan R.G. 2011. Fault Lines: How Hidden Fractures Still Threaten the World Economy. New Jersey: Princeton University Press. 280 p.

Rodrik D. 2020. Why Does Globalization Fuel Populism? Economics, Culture, and the Rise of Right-wing Populism. NBER Working Paper. No 27526. 49 p.

Rogoff K.S. 1990. Equilibrium Political Budget Cycles. The American Economic Review. Vol. 80. PP. 21-36.

Sandel M.J. 2020. The Tyranny of Merit. What's Become of the Common Good? New York: Farrar. Straus and Giroux. 288 p.

Schamis H.E., Way C.R. 2003. Political cycles and Exchange Rate-Based Stabilization. World Politics. Vol. 56. Iss. 1. PP. 43-78. DOI: https:// doi.org/10/1353/wp.2004.0007

Thornhill C., Smirnova M. 2018. Litigation and Political Transformation: the Case of Russia. Theory and Society. No 47. PP. 559-593. DOI: doi.org/10.1007/s11186-018-9327-5 
In citation: Belorusskiy Ekonomicheskiy zhurnal. 2021. No 1. PP. 59-69

Belarusian Economic Journal. 2021. No 1. PP. 59-69.

\section{POLITICAL BUSINESS CYCLE: INTERDISCIPLINARY STUDY OF ELECTORAL AND POST-ELECTORAL PERIODS}

\section{Kiryl Rudy ${ }^{1}$}

Author affiliation: ${ }^{1}$ Development Bank of the Republic of Belarus (Minsk, Belarus).

Corresponding author: Kiryl Rudy (kvrudy@gmail.com).

ABSTRACT. The article tests on the hypotheses about political business cycle by the case of 121 countries between 1991 and 2019. Regression analysis reveals budget political business cycle for countries with high level of economic development. Political business cycles among EAEU member countries and Ukraine from 1991 to 2019 are identified. They are namely: a monetary one typical of Belarus, Kyrgyzstan, Russia and Ukraine, budgetary in Armenia, Russia and Ukraine and general economic cycle in Kazakhstan.

KEYWORDS: political business cycle, political economy, economic policy.

JEL-code: D71, E32, H5, H6, O50, P16.

DOI: $10.46782 / 1818-4510-2021-1-59-69$

Received 22.01.2021 